\title{
Mental toughness in sport questionnaire - MTSQ
}

\author{
Jacek Przybylski \\ University of Gdansk, Gdansk, Poland
}

\section{BACKGROUND}

Stress resistance is very substantial and interesting for scientists, competitors, coaches, and psychologists. The main aim of the article was the psychometric examination of mental toughness in the sport questionnaire (MTSQ).

\section{PARTICIPANTS AND PROCEDURE}

The group of participants consisted of athletes presenting different levels of experience: Olympians, first-league, national team: $N=421$ athletes, including 190 women and 231 men, age $M=20.40, S D=5.30$. Test procedure: 124 statements were selected for exploratory factor analysis with the method of main components with rotation of intercorrelational orthogonal factors. It was used in order to check the factor structure of the tool and for the clear interpretation of isolated factors. As a result of the validation, 42 statements were finally selected measuring three dimensions of mental toughness. Each subscale consisted of
14 items. Next the reliability and the validity of the questionnaire were analysed.

RESULTS

The three-factor structure of the measured model of stress resistance accurately reflects the relation among stress resistances factors. Individual scales, at least mutually correlated, present accurate and reliable operationalisation of dimensions of the stress resistance.

\section{CONCLUSIONS}

The mental toughness in sport questionnaire (MTSQ) presents accurate and reliable operationalisation of stress resistance dimensions.

KEY WORDS

stress; sport psychology; mental toughness

Corresponding Author - Jacek Przybylski, Ph.D., University of Gdansk, 4 Bażyńskiego Str., 80-309 Gdansk, Poland, e-mail: psyjp@univ.gda.pl

Authors' CONtribution - A: Study design · B: Data collection · C: Statistical analysis · D: Data interpretation ·

E: Manuscript preparation · F: Literature search · G: Funds collection

TO CITE THIS ARTICLE - Przybylski, J. (2018). Mental toughness in sport questionnaire - MTSQ. Current Issues in

Personality Psychology, 6(1), 67-78.

RECEIVED 03.12.2016 · REVIEWED 18.01.2017 · ACCEPTED 21.08.2017 • PUBLISHED 14.12.2017 


\section{BACKGROUND}

For many years the problem of stress resistance has been substantial and of interest not only for scientists but also for competitors, coaches, and psychologists. In the term "mental toughness" are included a lot of different, significant factors without which the athlete would not be able to perform on the optimal level. Scientists are attempting to conceptualise this term by creating different scales in research measurements.

Resilience (Dyer \& McGuiness, 1996) is the ability to return swiftly to the state of equilibrium having undergone change, failure, or serious trouble. The most crucial elements here are: the ability to perform a correct analysis of events, the ability to find quick solutions, flexibility, and inner motivation.

Hardiness less susceptibility to stressful situations, effectiveness, flexibility in coping with stressful situations, positive attitude and managing the situation, involvement in managing and solving difficult situations, belief in one's ability to cope with adversity, and optimism (Kobasa, Maddi, \& Kahn, 1982; Kobasa, Maddi, Puccetti, \& Zola, 1985; Wiebe, 1991; Wiebe \& Williams, 1992).One of the components of mental resilience is emotional resilience, i.e. "the ability to act effectively in the face of strong negative emotions, or, alternatively, the ability to control one's emotions" (Gracz \& Sankowski, 2007).

Therefore, generally speaking, mental toughness involves: less susceptibility to stress, the ability to cope in a difficult situation, control, and flexibility.

Mental toughness is a feature of athletes that differentiate the world-class from the average and the winners from the losers. The mentally tough consistently perform up to or above their potential. Some people are "in the zone", while others fall apart as soon as competition starts. An athlete's mental preparation is as important as the physical preparation. A lot of factors negatively affect performance, for instance: pressure to perform or fear of failure, distractions, lack of self-confidence, and others. These are linked with physiological responses: breathing shallows, the heart races, the muscles tense, the mouth goes dry, and vision narrows (Skakoon, 2015).

James E. Loehr describes an "Ideal Performance State" that is calm, confident, energised, and joyful. Mental toughness is not only in sport but also in work and life (Loehr, 1983).

Gallwey (2014) in his book "The Inner Game of Tennis" presents classic examples, such as: "just knowing you need to calm down won't help. The specific techniques of relaxation, visualisation, and concentration will". There are proven techniques used to achieve proper mental state.

In the book "Mental Training for Peak Performance" (Ungerleider, 2005) the author writes that proper breathing "reduces stress and anxiety, and increases performance." Relaxation starts by controlling breathing. He recommends taking six full breaths, inhaling each over six seconds, holding for three seconds, exhaling for six and finally maintaining a comfortable, steady tempo thereafter. Then to slowly clench the hands into fists, hold for six seconds, then let them go limp. Continue with forearms, shoulders, chest, abs, legs, even the jaw. It helps to recognise that some muscles have been tensed without knowing it. This "progressive relaxation" should put the athlete into a calm but ready state.

Top athletes visualise their desired outcome. Skakoon (2015) gives some examples: Jack Nicklaus sees a putt roll into the hole before striking the ball; Lindsey Vonn, eyes closed, hands curving and twisting, imagines her run at the top of the downhill course. "See yourself succeed," Ungerleider (2005) writes. He recommends reliving the greatest successes, the happiest moments, and trying to recapture those feelings from those times. Smiling provokes a positive mindset (and frowning the opposite).

Another technique is focus. Concentrating is focusing on the immediate task. "Trying hard to concentrate doesn't work," Gallwey (2014) advises, adding that it comes naturally from an interest in the undertaking. It is misguided to intensely study or to repeat relentlessly immediately before a challenge. Of course, preparing well beforehand is imperative; it boosts confidence, enabling the ideal performance state. Many people benefit from a period of physical isolation. During the competition, concentration should consist of being "in the moment," "here and now," fully aware of everything, distracted by nothing. It is best to practice achieving an ideal performance state, which makes getting there easier when it is needed.

But even if the athlete masters mental toughness, he/she will be anxious and nervous at times. It should be learnt to savour these emotions. "It's so exhilarating!". Mental toughness training is beneficial for anyone. An ideal performance state can help with everything not only in sport - from interviews to confrontations to presentations. Relaxation, visualisation, and concentration are recommended (Skakoon, 2015).

There are some well-known toughness measurements in the world, e.g. MTI - Mental Toughness Measurements (Middleton, 2004), PPI - Psychological Performance Inventory - Alternative (Loehr, 1986), MTQ 48 - Mental Toughness Questionnaire 48 (Clough, 2012), SMTQ - Mental Toughness Questionnaire for sport (Sheard, Golby, \& Wersch 2009), and the AfMTI Australian football Mental Toughness Inventory - (Gucciardi, 2009),

The questionnaire of psychological resistance in the Mental Toughness Inventory (MTI; Middleton, Bog, Martin, Richards, \& Perry, 2004) consists of 65 items measuring 12 components. The MTI question- 
naire has a firm theoretical basis. However, the small amount of psychometric details concerning scales can be observed. Moreover, it can be noticed that the questionnaire concerns elite sports (low aged athletes from the secondary school between 12 to 19 years old). There is a need for further testing of the MTI in order to assess its psychometric properties.

The next questionnaire of the mental toughness is a 42-item orientated towards workmanship (Psychological Performance Inventory; Loehr, 1986) - one of the first questionnaires to include cognitive-behavioural factors and dimensions of self-assessment. Loehr offered the discussion concerning the scale, the concept, and theoretical basis of the tool but was not convincing enough, and in particular, no psychometric support for its practical application was described. Psychometric PPI analysis (Golby, Sheard, \& Wersch, 2007) established several arguments for the suggested seven-factor structure of the questionnaire. Finally, four factors of stress resistance were established, and these were labelled: determination, self-belief, positive cognition, and visualisation. Confirmatory factor analysis (CFA) confirmed the four-factor structure for the PPI-A. Nevertheless, the indicator of control is not included in the PPI-A, which is essential in stress resistance.

The next measurement is MTQ 48 (Mental Toughness Questionnaire), which was operationalised in business and management. Applying this measurement in athletes is linked with unverified statements of the good validity of this tool. Mental Toughness Questionnaire 48 (MTQ48; Clough, Earle, \& Sewell, 2002) contains 48 statements in a five-points Likert scale and with an average time of filling in of 10 to 15 minutes. The following scales can be distinguished: commitment, emotional control, life control, challenge, interpersonal confidence, and confidence in abilities. But, there are few published values of psychometric properties of the scale. There is little published evidence of the scale's psychometric properties. Its factor structure, in particular, has not been rigorously scrutinised using exploratory and confirmatory techniques. Furthermore, the scale's authors offered little rationale for the association with hardiness, which ultimately is the basis for the instrument's subscales. Its factor structure is not fully analysed strictly with confirming methods. Moreover, the authors offered few reasons for the connection of this scale with endurance, which is the base of stress resistance.

Another self-report instrument for the assessment of mental toughness is the Sports Mental Toughness Questionnaire (SMTQ; Sheard, Golby, \& Wersch, 2009). It is a 14-item questionnaire, which measures three factors: confidence, constancy, and control.

According to Sheard (2010), the confidence subscale measures athletes' belief in their own abilities to achieve goals and to be better than their opponents. Constancy reflects determination, personal responsibility, an unyielding attitude, and the ability to concentrate. Finally, control in the SMTQ is concerned with the perception that one is personally influential and can bring about desired outcomes with particular reference to controlling emotions. Sports Mental Toughness Questionnaire possesses satisfactory psychometric properties with adequate reliability, divergent validity and discriminative power.

The results revealed promising features of the SMTQ, lending preliminary support to the instrument's factorial validity and reliability. Further construct validation of the SMTQ is recommended, including its use as an index for evaluating the effect of intervention programs.

The next questionnaire is the AfMTI Australian football Mental Toughness Inventory (Gucciardi, 2009). Confirmatory factor analyses were applied in order to examine the factor structure of crucial instruments in Australian football. The questionnaire includes the awareness of the mental toughness in Australian football (Gucciardi, Gordon, \& Dimmock, 2008).

Correlations between the four-factor inventory and flow, resilience, and social desirability were examined. The discriminant validity of the inventory was also assessed. Multisource ratings (self, parent, and coach) of the AfMTI were examined in experiment two.

The AfMTI is a 24-item scale that measures four components of mental toughness in Australian football - thrive through challenge, sport awareness, tough attitude, and desire of success. It was shown to have adequate internal reliability estimates across different raters $(\alpha=.70-.89)$. Moderate correlations with flow and resilience were shown, while minimal correlations existed with social desirability. Multisource data were somewhat equivocal; correlational data suggested a disagreement between raters, whereas an ANOVA suggested agreement between raters.

In spite of the numerous theories concerning mental toughness there is a lack of a solid and accurate tool in this field in Poland. It was the main argument to construct the MTSQ (Mental Toughness in Sport Questionnaire), which measures three aspects of mental toughness:

- relations with the coach,

- burden of the training regime,

- negative states prior to performance.

In creating the Mental Toughness in Sport Questionnaire, evaluation of the reliability and validity of this tool were aims of the research.

\section{PARTICIPANTS AND PROCEDURE}

The purpose of this paper is to estimate the psychometric properties of the MTSQ scale dedicated to 
measure mental toughness. In order to achieve this objective, we followed the procedure proposed by Besharat (2010), which is probably the most adequate in the research of sport psychology. Accordingly, the following steps were taken: a) definition of the phenomenon was established, b) descriptions of observed indicators were collected, c) items of desired scale were selected, d) validity and reliability coefficients were estimated using exploratory analyses, and e) psychometric properties were confirmed using structural equation modelling.

Phenomenon definition. Mental toughness is defined as the ability to cope in difficult circumstances. The following factors contribute towards success: the ability to take up challenges, and the feeling of influence and control as well as involvement. People who display great hardiness are able to undergo a "mental transformation" in difficult situations and thus cope better with adversities (Kobasa, 1979).

Collecting descriptions of mental toughness. According to the second step of the Besharat (2010) procedure, sports academy students $(N=87)$ and students in sports clubs $(N=52)$ were asked to describe behaviours they observe in themselves or other people coping with sport stress and related to mental toughness defined as above. Over four hundred descriptions of behaviours were collected.

Primary scale item selection. Each of the descriptions were rewritten on a separate piece of paper to facilitate using them as parts of a mental map procedure (Skulberg, 2011). The contents of all descriptions were analysed and categorised in the focus study conducted in a group of $N=7$ specialists in sport psychology, linguists, and coaches. Their task was to read carefully each of the obtained descriptions written on a separate piece of paper and group them in clusters of behaviour with similar content. Then they were asked to formulate a short description of each category. The result was $k=124$ descriptions of behaviours related to mental toughness observed in sports, training, and other everyday sport activities.
The instruction was constructed in the following way: Decide which of the following factors appear in your life and to what extent they stress you, irritate you, bother you, or annoy you. Determine the severity of each of these factors on a scale of 0-10. An answer of 0 means that a given factor is completely neutral or absent for you. An answer of 1 means that these factors stress you or annoy you very little. An answer of 10 means that the factor stresses you or annoys you at a very high level.

\section{PARTICIPANTS}

Testing the properties of measurement. Items created by specialists were arranged in the form of a psychological inventory and tested for the psychometric properties in a convenient sample of $N=421$ athletes (called a test sample) including a variety of sports, presenting different levels of sport experience from regional to premier league. A detailed description of sample features is presented in the table below (Table 1).

Confirmation of the MTSQ factor structure. In order to confirm the MTSQ measurement properties and factor structure a convenient sample was taken of $N=212$ athletes (called a validation sample) including $n=160(75.50 \%)$ males and $n=52(24.50 \%)$ females aged from 12 to 28 years $(M=18.30, S D=2.20$, $Q_{2}=18$ ) representing a variety of sports. They were characterised by heterogeneous sport experience ranging from 1 to 18 years $(M=6.40, S D=3.40$, $Q_{2}=6$ years). Detailed demographic characteristics of the validation sample are presented in the table below (Table 2).

\section{RESULTS}

\section{FACTORIAL VALIDITY}

In order to examine the factorial structure of a desired scale and item discrimination for each of

Table 1

Demographic characteristics of validation sample $(N=421)$

\begin{tabular}{lc}
\hline Demographic characteristics & Descriptive statistics \\
\hline Age & $\begin{array}{c}\text { min }=14, \max =68, M=20.40, S D=5.30, \mathrm{Q}_{2}=19 \\
\text { Sex } \\
\text { Sport character }\end{array}$ \\
Temales $(n=159,37.80 \%)$, males $(n=262,62.20 \%)$ \\
Team sports $(n=266,63.30 \%)$, individual $(n=155,36.70 \%)$ \\
Less than 5 years $(n=127,30.17 \%), 5$ through $10(n=207,49.17 \%)$, \\
over 10 years $(n=87,20.67 \%)$,
\end{tabular}


Table 2

Demographic characteristics of the validation sample $(N=212)$

\begin{tabular}{|c|c|}
\hline Demographic characteristics & Descriptive statistics \\
\hline Age & $\min =12, \max =28, M=18.32, S D=2.23, Q_{2}=18$ \\
\hline Sex & Females $(n=52,24.50 \%)$, males $(n=160,75.50 \%)$ \\
\hline Sport character & Team sports $(n=70,33.00 \%)$, individual sports $(n=142,67.00 \%)$ \\
\hline Sports experience & $\begin{array}{c}\text { Less than } 5 \text { years }(n=90,42.50 \%), 5 \text { through } 10(n=92,43.40 \%), \\
\text { over } 10 \text { years }(N=18,8.50 \%), \\
\text { overall: } \min =.50, \max =18, M=6.37, S D=2.24, Q_{2}=6\end{array}$ \\
\hline Sporting achievement & $\begin{array}{c}\text { Premier league }(n=17,8.00 \%) \text {, national championship }(n=125,59.00 \%) \text {, } \\
\text { nationwide sports }(n=70,33.00 \%)\end{array}$ \\
\hline
\end{tabular}

Table 3

Summary of very structure sample (VSS) analysis determining the number of components describing mental toughness in sport situations

\begin{tabular}{lcccccccc}
\hline $\begin{array}{l}\text { Number } \\
\text { of extracted } \\
\text { components }\end{array}$ & $\chi^{2}$ & $d f$ & RMSEA & CFI & $\chi^{2}$ & $d f$ & RMSEA & CFI \\
\cline { 2 - 10 } & 492.81 & 373 & .18 & .67 & 453.52 & 374 & .12 & .63 \\
2 & 649.18 & 499 & .09 & .71 & 609.39 & 501 & .06 & .89 \\
3 & 743.24 & 626 & .09 & .78 & 717.11 & 629 & .09 & .80 \\
4 & 906.72 & 754 & .08 & .80 & 883.66 & 758 & .09 & .78 \\
5 & 1006.59 & 883 & .08 & .81 & 973.82 & 888 & .09 & .70 \\
\hline
\end{tabular}

$k=124$ descriptions of tough behaviours, an exploratory principal components analysis using varimax and oblimin rotation of extracted components was conducted. Burt's VSS test of structure revealed that a three-factorial model using oblimin rotation is probably the most explanatory in measuring the phenomenon $\left(\chi^{2}[501]=\right.$ 609.39, RMSEA $=.061, \mathrm{CFI}=.90)$. This model is satisfactory in the sense of the global fit indices, although it contains items with relatively small factor loadings. In order to compromise the reliability and validity of the measurement with the number of items included in MTSQ items characterised by factor loadings less than .50 for any of three subscales were excluded from the further analyses (Table 3).

Finally, $k=42$ items were selected to be a best representation of three correlated components. Principal component analysis using oblimin rotation of extracted components conducted in 42-item data established the factorial validity of the MTSQ measure. Results of the analysis are presented in the Table 4.

Below are presented samples of items from the MTSQ scale:

- relations with the coach:

- fear of falling short of the coach's expectations,

- lack of clarity as to the coach's assessment style;
- burden of the training regime:

- lengthy training sessions,

- allotment of extra activities;

- negative states prior to performance:

- fear of losing,

- pressure to win.

In order to verify the factorial structure of MTSQ a confirmatory factor analysis (CFA) using maximum likelihood estimation was conducted. In the desired model three factorial structures of non-orthogonal mental toughness components were represented as three latent variables reflecting adequate observed MTSQ items. The estimated model is nearly sufficient in a sense of global fit indices $\left[\chi^{2}(816)=2001.94\right.$, RMSEA $=.08, \mathrm{CFI}=.78]$. It means that the measure of mental toughness is valid to measure the mental strategy used in a sport situation according to coping with stress (Table 4).

Detailed inspection of factor loadings obtained in the CFA procedure revealed the existence of six items significantly decreasing the global model fit (Table 5) with standardised factor loadings $(\beta)$ of value less than .50. Due to the fact that the number of items in each estimated component is relatively large the author decided to exclude those irrelevant items from the confirmatory model. Results of followed-up CFA analysis revealed significant increase 
Table 4

Summary of structure matrix for three components extracted in principal analysis with oblimin rotation

\begin{tabular}{|c|c|c|c|c|}
\hline \multirow{2}{*}{$\begin{array}{l}\text { Label of extracted } \\
\text { components }\end{array}$} & \multirow[t]{2}{*}{ Item } & \multicolumn{3}{|c|}{ Component } \\
\hline & & A & B & $\mathrm{C}$ \\
\hline \multirow{15}{*}{$\begin{array}{l}\text { Negative states prior } \\
\text { to performance }\end{array}$} & 16 & .74 & .32 & .29 \\
\hline & 21 & .77 & .31 & .26 \\
\hline & 24 & .76 & .35 & .33 \\
\hline & 26 & .68 & .29 & .49 \\
\hline & 27 & .69 & .53 & .49 \\
\hline & 28 & .70 & .40 & .42 \\
\hline & 29 & .80 & .37 & .44 \\
\hline & 30 & .77 & .33 & .50 \\
\hline & 31 & .75 & .47 & .51 \\
\hline & 32 & .76 & .36 & .49 \\
\hline & 33 & .74 & .33 & .44 \\
\hline & 34 & .72 & .39 & .38 \\
\hline & 36 & .74 & .38 & .46 \\
\hline & 37 & .71 & .46 & .45 \\
\hline & 2 & .49 & .28 & .61 \\
\hline \multirow{12}{*}{$\begin{array}{l}\text { Relations with the } \\
\text { coach }\end{array}$} & 5 & .28 & .32 & .60 \\
\hline & 7 & .36 & .26 & .76 \\
\hline & 8 & .38 & .61 & .51 \\
\hline & 9 & .37 & .32 & .82 \\
\hline & 11 & .30 & .14 & .65 \\
\hline & 12 & .37 & .30 & .75 \\
\hline & 13 & .38 & .29 & .73 \\
\hline & 14 & .44 & .28 & .70 \\
\hline & 15 & .42 & .26 & .64 \\
\hline & 17 & .46 & .38 & .61 \\
\hline & 18 & .46 & .28 & .61 \\
\hline & 25 & .57 & .38 & .58 \\
\hline \multirow{15}{*}{$\begin{array}{l}\text { Burden of the } \\
\text { training regime }\end{array}$} & 35 & .38 & .24 & .58 \\
\hline & 1 & .21 & .66 & .15 \\
\hline & 3 & .23 & .52 & .10 \\
\hline & 4 & .28 & .59 & .23 \\
\hline & 6 & .23 & .68 & .24 \\
\hline & 10 & .39 & .69 & .49 \\
\hline & 19 & .40 & .72 & .27 \\
\hline & 20 & .29 & .72 & .31 \\
\hline & 22 & .32 & .73 & .32 \\
\hline & 23 & .34 & .57 & .24 \\
\hline & 38 & .49 & .74 & .33 \\
\hline & 39 & .30 & .50 & .23 \\
\hline & 40 & .26 & .67 & .22 \\
\hline & 41 & .28 & .53 & .20 \\
\hline & 42 & .42 & .72 & .30 \\
\hline
\end{tabular}


Table 4

(Table 4 continued)

\begin{tabular}{lrrr}
\hline Label of extracted & \multicolumn{3}{c}{ Component } \\
components & $\mathrm{A}$ & $\mathrm{B}$ & $\mathrm{C}$ \\
\cline { 2 - 4 } & 14.45 & 2.60 & 3.53 \\
Eigenvalue & 34.41 & 6.19 & 8.51 \\
Percentage of variance explained & .94 & .90 & .89 \\
Cronbach $\alpha$ for internal consistency & & \\
\hline
\end{tabular}

Table 5

Summary of global model fit estimates in validation sample during CFA analysis

\begin{tabular}{lcccc}
\hline & $\chi^{2}$ & $d f$ & RMSEA & CFI \\
\hline Uncorrelated (orthogonal) components & 2123.85 & 819 & .11 & .71 \\
Intercorrelated (non-orthogonal) components & 2001.94 & 816 & .08 & .78 \\
\hline
\end{tabular}

of model fit measured by global model fit indices $\left[\chi^{2}(524)=1277.56, \mathrm{RMSEA}=.08, \mathrm{CFI}=.80\right]$ and those estimates are very similar to those obtained in an exploratory analysis (Table 3 ).

As a result of excluding the insufficient items from scales of negative states and the relationship with the coach, the explanatory power of the model distinctly increased, specially in the case of scale orthogonality. Estimates of average (ASV) and maximum (MSV) shared variance between scale components decreased by about $2.00-3.00 \%$ according to the increase of average variance explained (AVE) by 1.00-3.00\%. Reassuming those findings the MTSQ scale can be considered as valid and reliable in the sense of an internal consistency measure of mental toughness. Reliability coefficients (CR) show high (over .80) internal consistency of three components of MTSQ; variance explained by all of components (AVE) is significantly higher than the variance shared with other components of toughness (ASV or MSV). Finally, the overall model is well fitted to the data gathered in a different population to that in which it was proposed. In conclusion, the model of measurement of mental toughness is likely to be highly general in a variety of sport disciplines and participants with different sport experience.

\section{CONVERGENT AND DISCRIMINANT VALIDITY}

In order to estimate the convergent and discriminant validity of MTSQ a validation sample (described in a previous part of the paper) was tested using measures of strategies of coping with stress CISS (Endler \& Parker, 1990) and the Inventory of perceived sources of stress (KPS; Plopa \& Makarowski, 2010). A detailed summary of the analysis is presented in the Table 7 .
Detailed inspection of the convergent validity estimated through correlations with measures of stress perceived and coping with stress revealed that mental toughness shares a meaningful variance with stress perceived in aspects of internal and external sources as well as emotional tension. It is especially interesting in conjunction with the positive relationship to emotional strategy of coping with stress. Additionally, inspection of validity indices reveals that variance shared by subscales of MTSQ with other measures is significantly less than variance explained by the component, which means that MTSQ is convergent but not identical to measures of perceived stress and coping with stress specially in its emotional aspects.

Discriminant validity of the MTSQ scale was tested in series of one-way ANOVAs using demographic characteristics of the validation sample (Table 2) as fixed factors explaining the scores of MTSQ subscales. The results are presented in the Table 8.

Results of discriminant validity of MTSQ measure conducted against demographic characteristics of athletes revealed strong discrimination of MTSQ against sex, which explains the $3.00 \%$ (in burden of training regime and relations to the coach) to $12.00 \%$ (in negative states prior to performance) variance and is the most meaningful factor discriminating mental toughness. Analyses revealed a significant discrimination of negative states prior to performance and relations to the coach against the character of the sport - individual vs. team.

\section{DISCUSSION}

The purpose of this paper was to examine the psychometrical properties of MTSQ. In order to achieve that objective the procedure proposed by Besharat, 2010 was conducted. In a few steps the process start- 
Table 6

Summary of factor loadings obtained in CFA model assuming non-orthogonal factor structure before and after excluding insufficient items

\begin{tabular}{|c|c|c|c|c|c|c|c|c|c|}
\hline \multirow[t]{3}{*}{ Component } & \multirow[t]{3}{*}{$\begin{array}{l}\text { Scale } \\
\text { item }\end{array}$} & \multicolumn{4}{|c|}{$\begin{array}{c}\text { Item loadings and reliability estimates } \\
\text { before excluding insufficient items }\end{array}$} & \multicolumn{4}{|c|}{$\begin{array}{l}\text { Item loadings and reliability estimates } \\
\text { after excluding insufficient items }\end{array}$} \\
\hline & & \multicolumn{2}{|c|}{$\begin{array}{l}\text { Unstan- } \\
\text { dardized }\end{array}$} & \multirow{2}{*}{$\frac{\begin{array}{c}\text { Standa- } \\
\text { rdized }\end{array}}{\mathrm{b}}$} & \multirow[t]{2}{*}{ Reliability } & \multicolumn{2}{|c|}{$\begin{array}{l}\text { Unstan- } \\
\text { dardized }\end{array}$} & \multirow{2}{*}{$\begin{array}{c}\begin{array}{c}\text { Standa- } \\
\text { rdized }\end{array} \\
\text { b }\end{array}$} & \multirow[t]{2}{*}{ Reliability } \\
\hline & & $B$ & S.E. & & & $B$ & S.E. & & \\
\hline \multirow{14}{*}{$\begin{array}{l}\text { Negative } \\
\text { states prior to } \\
\text { performance }\end{array}$} & 16 & 1.00 & & .68 & & 1.00 & & .70 & \multirow{14}{*}{$\begin{aligned} \mathrm{CR} & =.98 \\
\mathrm{AVE} & =84.10 \% \\
\mathrm{ASV} & =43.40 \% \\
\mathrm{MSV} & =49.90 \%\end{aligned}$} \\
\hline & 21 & 1.11 & .11 & .78 & & 1.13 & .10 & .82 & \\
\hline & 24 & 1.12 & .11 & .78 & & 1.17 & .10 & .84 & \\
\hline & 26 & 1.00 & .11 & .68 & & .97 & .11 & .68 & \\
\hline & 27 & .81 & .10 & .58 & & & & & \\
\hline & 28 & 1.10 & .11 & .74 & $\mathrm{CR}=.98$ & 1.03 & .11 & .72 & \\
\hline & 29 & .88 & .10 & .67 & AVE $=81.30 \%$ & .79 & .09 & .62 & \\
\hline & 30 & 1.07 & .10 & .80 & $\mathrm{ASV}=47.40 \%$ & & & & \\
\hline & 31 & 1.08 & .17 & .46 & $M S V=49.70 \%$ & & & & \\
\hline & 32 & 1.01 & .10 & .73 & & .93 & .10 & .70 & \\
\hline & 33 & .89 & .10 & .64 & & .81 & .10 & .60 & \\
\hline & 34 & .89 & .10 & .63 & & & & & \\
\hline & 36 & 1.05 & .11 & .73 & & & & & \\
\hline & 37 & .90 & .10 & .65 & & .85 & .10 & .64 & \\
\hline \multirow{13}{*}{$\begin{array}{l}\text { Relations } \\
\text { with the } \\
\text { coach }\end{array}$} & 2 & 1.00 & & .58 & & 1.00 & & .59 & \multirow{13}{*}{$\begin{aligned} \mathrm{CR} & =.98 \\
\mathrm{AVE} & =79.20 \% \\
\mathrm{ASV} & =37.70 \% \\
\mathrm{MSV} & =46.90 \%\end{aligned}$} \\
\hline & 5 & 1.00 & .15 & .56 & & 1.00 & .15 & .56 & \\
\hline & 7 & 1.26 & .16 & .66 & & 1.31 & .17 & .68 & \\
\hline & 8 & 1.15 & .16 & .59 & & 1.16 & .16 & .60 & \\
\hline & 9 & 1.38 & .17 & .71 & & 1.44 & .17 & .75 & \\
\hline & 11 & 1.01 & .14 & .60 & $\mathrm{CR}=.98$ & & & & \\
\hline & 12 & 1.20 & .15 & .72 & AVE $=78.20 \%$ & 1.21 & .15 & .73 & \\
\hline & 13 & 1.48 & .17 & .78 & $\mathrm{ASV}=39.00 \%$ & 1.49 & .17 & .79 & \\
\hline & 14 & 1.32 & .16 & .75 & $\mathrm{MSV}=45.40 \%$ & 1.24 & .15 & .72 & \\
\hline & 15 & 1.34 & .16 & .72 & & 1.31 & .16 & .71 & \\
\hline & 17 & 1.21 & .16 & .62 & & 1.13 & .16 & .58 & \\
\hline & 18 & 1.09 & .14 & .70 & & & & & \\
\hline & 25 & 1.06 & .15 & .59 & & & & & \\
\hline \multirow{15}{*}{$\begin{array}{l}\text { Burden of } \\
\text { the training } \\
\text { regime }\end{array}$} & 35 & 1.18 & .16 & .62 & \multirow{15}{*}{$\begin{aligned} \mathrm{CR} & =.96 \\
\mathrm{AVE} & =65.00 \% \\
\mathrm{ASV} & =40.90 \% \\
\mathrm{MSV} & =49.30 \%\end{aligned}$} & 1.18 & .16 & .62 & \multirow{15}{*}{$\begin{aligned} \mathrm{CR} & =.96 \\
\mathrm{AVE} & =65.00 \% \\
\mathrm{ASV} & =34.20 \% \\
\mathrm{MSV} & =39.90 \%\end{aligned}$} \\
\hline & 1 & .68 & .09 & .53 & & .68 & .09 & .53 & \\
\hline & 3 & .43 & .08 & .40 & & .43 & .08 & .50 & \\
\hline & 4 & .76 & .09 & .57 & & .76 & .09 & .57 & \\
\hline & 6 & .80 & .11 & .53 & & .80 & .11 & .53 & \\
\hline & 10 & .90 & .10 & .62 & & .90 & .10 & .62 & \\
\hline & 19 & .84 & .09 & .66 & & .84 & .09 & .66 & \\
\hline & 20 & .84 & .10 & .60 & & .84 & .10 & .60 & \\
\hline & 22 & .89 & .11 & .57 & & .89 & .11 & .57 & \\
\hline & 23 & .97 & .10 & .68 & & .97 & .10 & .68 & \\
\hline & 38 & .96 & .09 & .74 & & .96 & .09 & .74 & \\
\hline & 39 & .49 & .08 & .41 & & .49 & .08 & .51 & \\
\hline & 40 & .88 & .11 & .55 & & .88 & .11 & .55 & \\
\hline & 41 & .70 & .10 & .49 & & .70 & .10 & .51 & \\
\hline & 42 & 1.00 & & .77 & & 1.00 & & .77 & \\
\hline
\end{tabular}


Jacek Przybylski

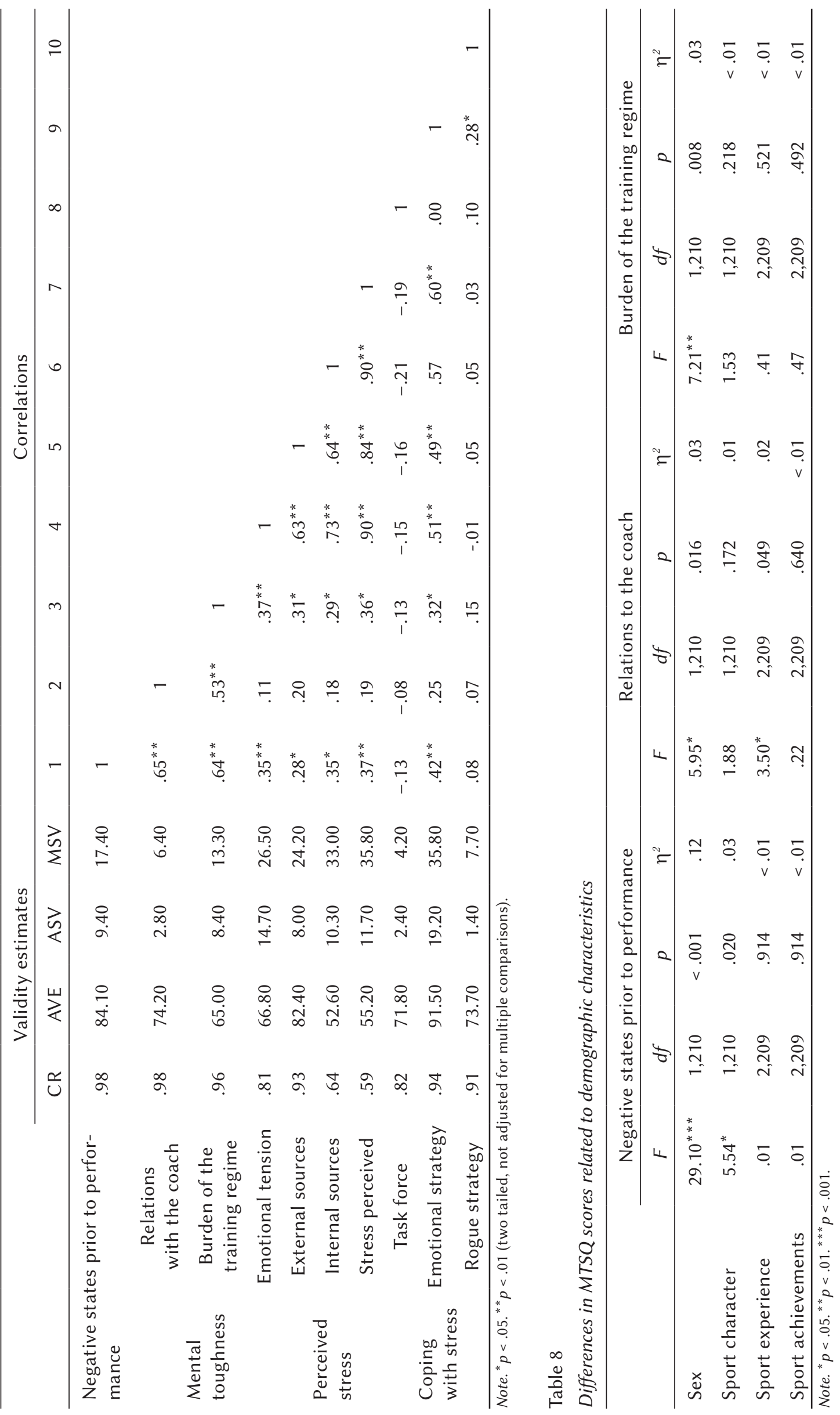


Table 9

Descriptive statistics of MTSQ results in validation sample $(n=212)$

\begin{tabular}{|c|c|c|c|c|c|c|c|}
\hline \multirow{2}{*}{\multicolumn{2}{|c|}{ Demographic characteristics }} & \multicolumn{2}{|c|}{$\begin{array}{c}\text { Negative states } \\
\text { prior to } \\
\text { performance }\end{array}$} & \multicolumn{2}{|c|}{$\begin{array}{l}\text { Relations to the } \\
\text { coach }\end{array}$} & \multicolumn{2}{|c|}{$\begin{array}{l}\text { Burden of the } \\
\text { training regime }\end{array}$} \\
\hline & & M & $S D$ & M & $S D$ & $M$ & $S D$ \\
\hline \multirow{2}{*}{ Sex } & Males $(n=160)$ & 45.10 & 30.07 & 56.52 & 31.70 & 44.14 & 25.67 \\
\hline & Females $(n=52)$ & 70.48 & 27.52 & 68.94 & 32.56 & 54.83 & 22.46 \\
\hline \multirow{2}{*}{$\begin{array}{l}\text { Sport } \\
\text { character }\end{array}$} & Team $(n=70)$ & 58.47 & 33.20 & 63.88 & 33.57 & 49.81 & 25.89 \\
\hline & Individual $(n=142)$ & 47.81 & 29.92 & 57.44 & 31.53 & 45.26 & 24.95 \\
\hline \multirow{3}{*}{$\begin{array}{l}\text { Sport } \\
\text { experience }\end{array}$} & Less than 5 years $(n=90)$ & 52.22 & 31.64 & 56.43 & 31.14 & 46.51 & 26.27 \\
\hline & 5 through $10(n=93)$ & 49.23 & 30.33 & 59.13 & 32.84 & 45.50 & 23.95 \\
\hline & Over 10 years $(n=29)$ & 55.28 & 34.34 & 70.69 & 32.71 & 51.62 & 26.72 \\
\hline \multirow{3}{*}{$\begin{array}{l}\text { Sport } \\
\text { achieve- } \\
\text { ments }\end{array}$} & Premier league $(n=17)$ & 53.94 & 31.43 & 74.76 & 24.89 & 43.24 & 21.42 \\
\hline & National championship $(n=125)$ & 52.15 & 32.38 & 56.47 & 33.58 & 46.53 & 26.32 \\
\hline & Nationwide sports $(n=70)$ & 49.23 & 29.81 & 61.40 & 30.65 & 48.04 & 24.50 \\
\hline
\end{tabular}

ing from definition of the phenomenon and collecting descriptions of tough behaviours, a final subset of 42 items was established as a valid and reliable representation of concept of mental toughness in sport. Principal component analysis revealed three factorial structures of measurement.

Negative state prior to performance (examples of items: fear of losing, pressure to win). This scale includes items related to emotional reactions to stress like fear, attention, feelings of pressure. Higher scores indicate lower toughness. High scores in this scale are characterised by severe stress before the start of or during the competition. Competitors who achieve high scores experience maximum levels of fear of failure or defeat. Low scores in this scale represent lower levels of feeling stress, fear, ability to cope in a difficult situation (before or during the start). Mental toughness by characterised by low scores in this scale.

Relations with the coach (examples of items: fear of falling short of the coach's expectations, lack of clarity as to the coach's assessment style). Results in this scale indicate the level of stress of the competitor towards the coach from his perspective. High scores express anxiety concerning e.g. displeasure of the coach about the result or his/her expectations, concerning conflicts with the coach, indifference of the coach, or lack of greater interest of the coach. Low scores in this scale indicate the opposite situation, meaning the athlete is more resilient to problems of this type in relation to the coach.

Burden of the training regime (examples of items: lengthy training sessions, allotment of extra activities). High scores in this scale show weaker resistance towards training and raised levels of stress con- cerning e.g. long-term training, overburdening tasks, additional work or other activities, doubts about one's preparation, and overload of activities. Low scores characterise a person who is well adapted and immune to abovementioned statements.

The three-factor model is well fitted to the data gathered in the population in which it was proposed. Furthermore, MTSQ is convergent but not identical to measures of perceived stress and coping with stress, especially in its emotional aspects.

All conducted analysis supported the thesis that MTSQ is valid to measure the mental strategy used in a sport situation. The imperfection of the tool is that the MTSQ questionnaire refers to the narrow specific group of highly-qualified athletes because of the construction of some specific items. In professional sport it can be observed that there is a high level of stress associated with scales. This is evidence that there is a need for the diagnosis and optimum functioning of the body including stress resistances. Mental toughness regards the control of many other essential and detailed factors in sport, so a good practice is the construction of questionnaires concerning stress resistance in specific sports disciplines, e.g. the AfMTI Australian football Mental Toughness Inventory - (Gucciardi, 2009), and the CMTI Cricket Mental Toughness Inventory (Gucciardi \& Gordon, 2009).

The main purpose of future research is further validation of the MTSQ questionnaire. Among others, a larger number of people should be involved in the analysis and comparison should be made with other groups and disciplines of highly qualified athletes. The next aim will be adjustment of the MTSQ to all groups of athletes not only those who are highly qualified. 
Global model fit estimates $\chi^{2}(254)=1277.56 ; p<.000 ;$ $\mathrm{RMSEA}=.08 ; \mathrm{P}-\mathrm{CLOSE}=.00$; $\mathrm{CFI}=.79 ; \mathrm{RFI}=.67$

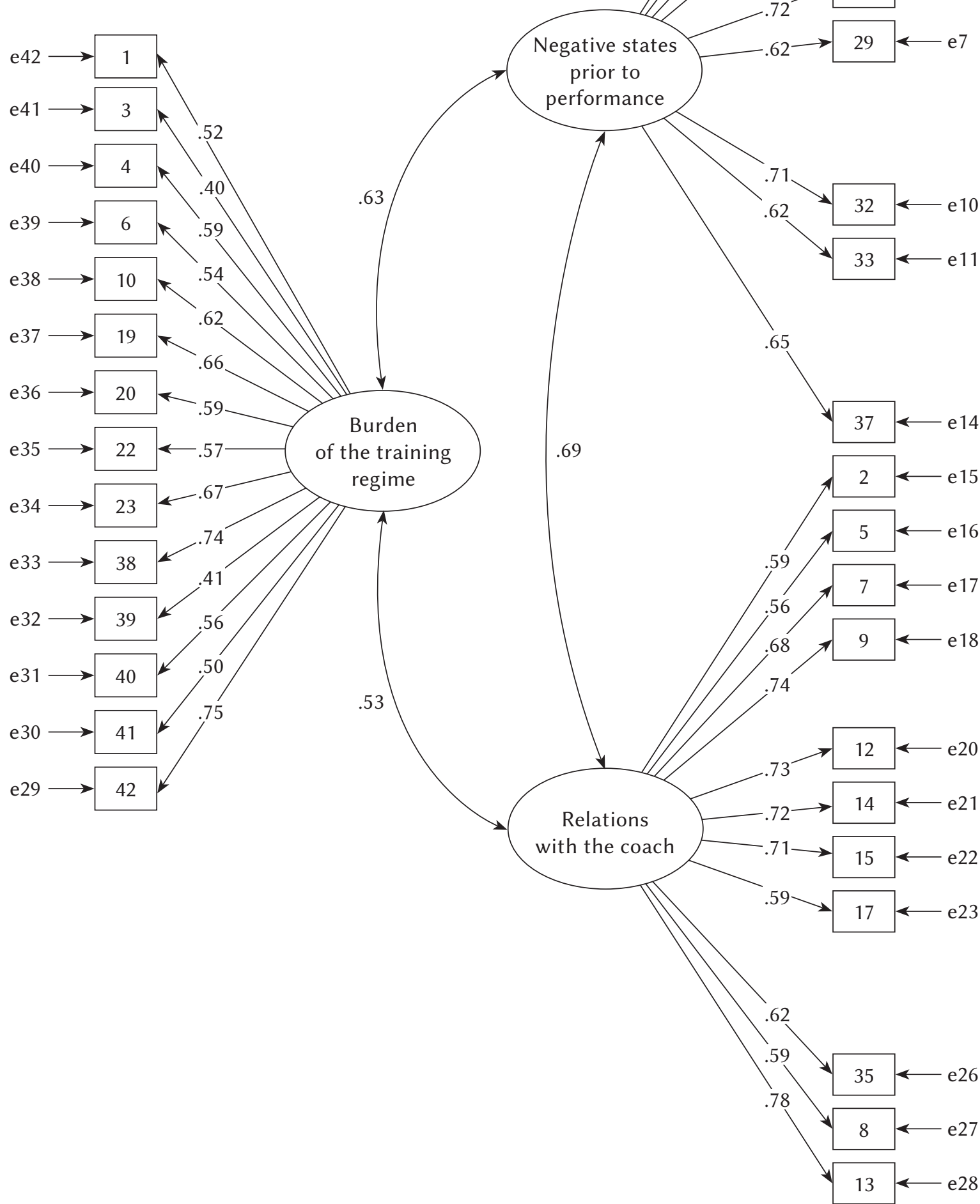

Figure 1. Results of the analysis of measurement model confirmed in MTSQ structure. 


\section{References}

Besharat, M. A. (2010). Psychometric properties of the sport stress coping styles scale. Procedia - Social and Behavioral Sciences (Vol. 5, pp. 609-613).

Clough, P., Earle, K., \& Sewell, D. (2002). Mental toughness: the concept and its measurement. In I. Cockerill (Ed.), Solutions in sport psychology (pp. 32-45). London: Thompson.

Clough, P., \& Strycharczyk, D. (2012). Mental toughness and its role in the development of young people. Coaching in Education: Getting Better Results for Students, Educators and Parents, 75-91.

Dyer, J. G., \& McGuinness, T. M. (1996). Resilience: Analysis of the concept. Archives of Psychiatric Nursing, 10, 276-282.

Endler, N. S., \& Parker, J. D. (1990). Multidimensional assessment of coping: a critical evaluation. Journal of Personality and Social Psychology, 58, 844-854.

Gallwey, W. T. (2014). The inner game of tennis: The classic guide to the mental side of peak performance. Macmillan.

Gracz, J., \& Sankowski, T. (2007). Psychologia aktywności sportowej [Psychology of sports activity]. Poznań: Akademia Wychowania Fizycznego.

Golby, J., Sheard, M., \& Van Wersch, A. (2007). Evaluating the factor structure of the psychological performance inventory. Perceptual and Motor Skills, 105, 309-325.

Gucciardi, D. F., Gordon, S., \& Dimmock, J. A. (2008). Towards an understanding of mental toughness in Australian football. Journal of Applied Sport Psychology, 20, 261-281.

Gucciardi, D. F., Gordon, S., \& Dimmock, J. A. (2009). Advancing mental toughness research and theory using personal construct psychology. International Review of Sport and Exercise Psychology, 2, 54-72.

Hanton, S., \& Connaughton, D. (2002). Perceived control of anxiety and its relationship to self-confidence and performance. Research Quarterly for Exercise and Sport, 73, 87-97.

Howell, D. C. (2013). Statistical Methods for Psychology $\left(8^{\text {th }}\right.$ ed $)$. University of Vermont.

Kobasa, S. C. (1979). Stressful life events, personality, and health: an inquiry into hardiness. Journal of Personality and Social Psychology, 37, 1-11.

Kobasa, S. C., Maddi, S. R., \& Kahn, S. (1982). Hardiness and health: a prospective study. Journal of Personality and Social Psychology, 42, 168-177.

Kobasa, S. C. O., Maddi, S. R., Puccetti, M. C., \& Zola, M. A. (1985). Effectiveness of hardiness, exercise and social support as resources against illness. Journal of Psychosomatic Research, 29, 525-533.

Loehr, J. E. (1983). The ideal performance state. Science Periodical on Research and Technology in Sport, 1, 1-7.
Loehr, J. E. (1986). Mental toughness training for sports: Achieving athletic excellence. Penguin Books.

Middleton, S. C., Marsh, H. W., Martin, A. J., Richards, G. E., Savis, J., Perry, Jr, C., \& Brown, R. (2004). The Psychological Performance Inventory: Is the mental toughness test tough enough? International Journal of Sport Psychology.

Plopa, M., \& Makarowski, R. (2010). Kwestionariusz poczucia stresu [Perceived Stress Questionnaire]. Warszawa: Pracownia Testów Psychologicznych.

Sheard, M., Golby, J., \& Van Wersch, A. (2009). Progress toward construct validation of the Sports Mental Toughness Questionnaire (SMTQ). European Journal of Psychological Assessment, 25, 186-193.

Sheard, M., \& Golby, J. (2010). Personality hardiness differentiates elite-level sport performers. International Journal of Sport and Exercise Psychology, 8, 160-169.

Skakoon, J. G. (2015). Mechanical Engineering. Computers \& Applied Sciences Complete, 10, 16.

Skulberg, H. (2011). Exploring Mental Scaling as Source for Creativity during the Product Design Process. Proceedings of E\&PDE 2011, the $13^{\text {th }}$ International Conference on Engineering and Product Design Education, London, UK, 08.-09.09.2011.

Ungerleider, S. (2005). Mental training for peak performance: Top athletes reveal the mind exercises they use to excel. Rodale.

Wiebe, D. J. (1991). Hardiness and stress moderation: A test of proposed mechanisms. Journal of Personality and Social Psychology, 60, 89-90.

Wiebe, D. J., \& Williams, P. G. (1992). Hardiness and health: A social psychophysiological perspective on stress and adaptation. Journal of Social and Clinical Psychology, 11, 238-262. 